\title{
Application of Digital Remote Wireless Microphone Technology in Single-Sided Deaf Cochlear Implant Recipients
}

\author{
Thomas Wesarg $^{1} \quad$ Yvonne Stelzig $^{2}$ Dan Hilgert-Becker ${ }^{3} \quad$ Bjorn Kathage $^{3} \quad$ Konstantin Wiebe $^{1}$ \\ Antje Aschendorff ${ }^{1}$ Susan Arndt ${ }^{1}$ Iva Speck ${ }^{1}$
}

${ }^{1}$ Department of Otorhinolaryngology - Head and Neck Surgery,
Medical Center - University of Freiburg, Faculty of Medicine,
University of Freiburg, Freiburg, Germany
2 Department of Otorhinolaryngology - Head and Neck Surgery,
Bundeswehrzentralkrankenhaus Koblenz, Koblenz, Germany
${ }^{3}$ Cl-Centrum Rhein-Mosel-Lahn am Bundeswehrzentralkrankenhaus
Koblenz, Koblenz, Germany

J Am Acad Audiol 2020;31:246-256.

\begin{abstract}
Address for correspondence Thomas Wesarg, Department of Otorhinolaryngology - Head and Neck Surgery, Medical Center University of Freiburg, Faculty of Medicine, University of Freiburg, D-79106 Freiburg, Germany

(e-mail: thomas.wesarg@uniklinik-freiburg.de).
\end{abstract}

\begin{abstract}
Keywords

- cochlear implant

- remote wireless microphone system

- single-sided deafness

- speech recognition in noise

Background Previous research showed benefits of remote wireless technology in bilaterally moderate- to-severe hearing-impaired participants provided with hearing aid(s), cochlear implant(s) (Cls), or bimodal devices as well as in single-sided deaf (SSD) cochlear implant recipients (with $\mathrm{Cl}$ from Cochlear ${ }^{\mathrm{TM}}$ ) and normal-hearing ( $\mathrm{NH}$ ) participants.

Purpose To evaluate the effect of the digital remote wireless microphone system, Roger $^{\mathrm{TM}}$, on speech recognition at different levels of multisource noise in SSD CI recipients using MED-EL CI sound processor OPUS 2. Outcomes were assessed as a function of the listening condition ( $\mathrm{NH}$ only, $\mathrm{NH}+\mathrm{Cl}, \mathrm{NH}+\mathrm{ClRog}, \mathrm{NHRog}+\mathrm{Cl}$, and NHRog + CIRog), Roger ${ }^{\mathrm{TM}}$ receiver type (Roger ${ }^{\mathrm{TM}}$ Focus for NH; Roger ${ }^{\mathrm{TM}} \mathrm{Xand}^{\mathrm{R}}$ Roger $^{\mathrm{TM}}$ MyLink for $\mathrm{Cl}$ ) and accessory mixing ratio.

Study Sample Eleven adult, SSD participants aided with CI from MED-EL.

Data Collection and Analysis Speech recognition in noise was assessed in two noRoger $^{\mathrm{TM}}$ conditions, one Roger ${ }^{\mathrm{TM}} \mathrm{X}$ condition, and two Roger ${ }^{\mathrm{TM}}$ MyLink conditions. For the Roger $^{\mathrm{TM}} X$ and no-Roger ${ }^{\mathrm{TM}}$ conditions, speech recognition was tested at $60.3 \mathrm{~dB}(\mathrm{~A})$ with the Oldenburg Sentence Test in classroom noise at levels of 55,65 , and $75 \mathrm{~dB}(\mathrm{~A})$. For the two Roger ${ }^{\mathrm{TM}}$ MyLink conditions, speech recognition at $60.3 \mathrm{~dB}(\mathrm{~A})$ was measured at a noise level of $75 \mathrm{~dB}(\mathrm{~A})$. Roger $^{\mathrm{TM}} X$ was assessed with an accessory mixing ratio of 1:1 (summation of unattenuated microphone and audio accessory input). For Roger ${ }^{T M}$ MyLink, two accessory mixing ratios were investigated, MT (1:1, summation of unattenuated microphone and telecoil input) and T with maximum attenuation of microphone input.

Results Speech recognition at higher noise levels (65 and $75 \mathrm{~dB}(\mathrm{~A})$ ) improved significantly with Roger $^{\mathrm{TM}}$ in both unilateral use conditions ( $\mathrm{NH}+\mathrm{CIRog}$ and $\mathrm{NHRog}+\mathrm{Cl}$ ) as well as bilateral use condition (NHRog $+\mathrm{ClRog}$ ). Both the bilateral application of Roger ${ }^{\mathrm{TM}}$ and the unilateral Roger ${ }^{\mathrm{TM}}$ application on the $\mathrm{NH}$ ear outperformed the Roger ${ }^{\mathrm{TM}}$ application on $\mathrm{Cl}$ alone. There was no statistically significant
\end{abstract}

Copyright $\odot 2020$ by the American Academy of Audiology. All rights reserved. Thieme Medical Publishers, Inc., 333 Seventh Avenue, New York, NY 10001, USA. Tel: +1(212) 760-0888.
DOI https://doi.org/ 10.3766/jaaa. 18060 . ISSN 1050-0545. 
effect of type of $\mathrm{Cl}$ Roger $^{\mathrm{TM}}$ receiver (Roger ${ }^{\mathrm{TM}} \mathrm{X}$ or Roger ${ }^{\mathrm{TM}}$ MyLink) and the accessory mixing ratio (MT or $\mathrm{T}$ ) on speech recognition.

Conclusions Speech recognition for distant speakers in multisource noise improved significantly with the application of Roger ${ }^{\mathrm{TM}}$ in SSD Cl recipients. Both the unilateral Roger $^{\mathrm{TM}}$ application on the $\mathrm{NH}$ ear or the $\mathrm{Cl}$ as well as the bilateral Roger $^{\mathrm{TM}}$ application can be recommended.

\section{Introduction}

Single-sided deaf (SSD) participants report difficulties with speech recognition in competing noise and localization of sound sources. Since 2008, cochlear implantation of SSD adults has been shown to be a successful treatment allowing for significant improvements of speech recognition in competing noise as well as localization of sound sources (Lieu, 2004; ${ }^{13}$ Vermeire and Van de Heyning, 2009; ${ }^{22}$ Buechner et al, 2010; ${ }^{4}$ Arndt et al, 2011; ${ }^{2}$ Jacob et al, 2011; $;^{11}$ Firszt et al, 2012; Tavora-Vieira et al, $2015 ;{ }^{20}$ Friedmann et al, 2016; ${ }^{8}$ Arndt et al, $2017^{3}$ ). Even so, SSD cochlear implant $(\mathrm{CI})$ recipients experience limited speech recognition in challenging listening situations, especially during conferences, in classrooms, and in reverberating rooms (Giolas and Wark, $1967 ;^{9}$ Wie et al, $2010^{28}$ ).

Wireless remote microphone systems have been designed to improve speech recognition of hearing- impaired participants in those challenging listening situations. These systems are intended to bridge the distance between a remote speaker and the listener using a microphone transmitter put near to the mouth of the speaker and a receiver connected to the listener's hearing aid (HA), $\mathrm{CI}$, or $\mathrm{NH}$ ear via wireless audio signal transmission. Conventional wireless remote microphone systems are fixed-gain or adaptive-gain (dynamic) frequency modulation (FM) systems. In 2013, Phonak AG (Stafa, Switzerland) introduced an advanced remote wireless microphone system, Roger ${ }^{\mathrm{TM}}$, that consists of a wireless microphone (e.g., Roger ${ }^{\mathrm{TM}}$ Pen) and one or several receivers (e.g., Roger ${ }^{\mathrm{TM}}$ Focus) compatible with most of the recent $\mathrm{CI}$ processors and HAs (Phonak AG, 2013 ${ }^{14}$ ). Because the receiver gain is automatically adjusted according to ambient noise level, Roger ${ }^{\mathrm{TM}}$ allows for good speech recognition, especially at higher competing noise levels (Thibodeau, 2014 ${ }^{21}$ ).

Benefits of remote wireless technology in participants with bilateral hearing loss using $\mathrm{HA}(\mathrm{s})$ or/and $\mathrm{CI}(\mathrm{s})$ were shown in former studies. Wolfe et al $(2013)^{30}$ revealed that Roger ${ }^{\mathrm{TM}}$ significantly improved speech recognition at higher noise levels $(70,75$, and $80 \mathrm{~dB}(\mathrm{~A}))$ and outperformed fixed-gain and adaptive-gain analogue FM systems in adult bilateral CI recipients and bimodal CI-HA recipients. These results were confirmed by Thibodeau (2014), ${ }^{21}$ demonstrating a significant benefit of Roger ${ }^{\mathrm{TM}}$ compared with FM technology (fixed- and adaptive-gain) in bilateral HA users. Furthermore, Wolfe et al $(2015)^{29}$ measured speech recognition in classroom noise ranging in level from 50 to $80 \mathrm{~dB}(\mathrm{~A})$ in a classroom in three unilateral and eight bilateral $C I$ recipients, ages 11-68 years, using $\mathrm{CI}$ from Advanced Bionics AG (AB; Stafa, Switzerland).
They were able to show that the use of Roger ${ }^{\mathrm{TM}}$ technology (Roger ${ }^{\mathrm{TM}}$ inspiro transmitter, Roger ${ }^{\mathrm{TM}} 17$ receiver) significantly improved speech recognition. De Ceulaer et al $(2016)^{5}$ assessed speech reception thresholds in seven unilateral and five bimodal $A B C I$ recipients in a diffuse field of multitalker babble noise generated by three nonsimultaneous companion talkers simulating a group conversation situation at a table in a restaurant environment. For the application of a Roger ${ }^{\mathrm{TM}} 17$ receiver connected to the recipients' $\mathrm{CI}$ sound processor and one Roger ${ }^{\mathrm{TM}}$ Pen transmitter in the middle of the table, the authors could demonstrate a significant improvement of speech reception thresholds, and an additional improvement for the application of three Roger ${ }^{\mathrm{TM}}$ Pen transmitters used by each talker in a microphone network.

Other advanced remote wireless microphone systems, Mini Microphones 1 and 2+, also enabled a significant improvement of speech recognition in noise in unilateral or bilateral CI recipients as well as bimodal CI-HA users (De Ceulaer et al, $2017^{6}$ ). In bimodal recipients, the application of Mini Microphone 2+ on both the $\mathrm{Cl}$ and HA yielded a significant improvement compared with unilateral use with the CI only (Vroegop et al, 2017 ${ }^{24}$ ). Furthermore, the benefits of remote wireless microphone systems were shown for pediatric unilateral and bilateral $\mathrm{CI}$ recipients with bilateral hearing loss (Schafer and Thibodeau, 2006 ${ }^{19}$; Razza et al, $2017^{18}$ ). In addition, Razza et al $(2017)^{18}$ assessed the improvement of speech reception threshold in noise in bilaterally hearing-impaired unilateral or bilateral CI children using two different remote wireless systems and found a significantly better speech performance with the Mini Microphone 1 compared with Roger ${ }^{\mathrm{TM}}$. Furthermore, we were able to demonstrate the benefits ofthe remote wireless technology, Roger ${ }^{\mathrm{TM}}$, in SSD participants provided with a CI from Cochlear Ltd. (Sydney, Australia) and normal-hearing (NH) participants (Wesarg et al, 201927). Both SSD CI recipients and $\mathrm{NH}$ participants benefited from the unilateral application of Roger $^{\mathrm{TM}}$ on the $\mathrm{NH}$ ear, on the $\mathrm{CI}$ as well as from using Roger $^{\mathrm{TM}}$ bilaterally, and no difference was revealed between the applications (Wesarg et al, 2019 ${ }^{17}$ ).

With the Roger ${ }^{\mathrm{TM}}$, different microphone transmitters (Roger $^{\mathrm{TM}}$ Pen, Roger ${ }^{\mathrm{TM}}$ Touchscreen Mic or Roger ${ }^{\mathrm{TM}}$ Table Mic) can be combined with various receivers ( Roger $^{\mathrm{TM}}$ X, Roger ${ }^{\mathrm{TM}}$ MyLink or Roger ${ }^{\mathrm{TM}}$ Focus) (Phonak AG, 2013; ${ }^{14}$ Phonak AG, 2016; ${ }^{15}$ Phonak AG, 2017 ${ }^{16}$ ). An audio input socket is required to attach Roger ${ }^{\mathrm{TM}} \mathrm{X}$ to a hearing device (HA or CI processor), whereas the Roger ${ }^{\mathrm{TM}}$ MyLink neckloop requires an integrated telecoil in the hearing device. Using 
Roger $^{\mathrm{TM}}$ MyLink, different mixing ratios between the input from the CI sound processor or HA microphone(s) and the input from coupled audio accessories can be selected. The accessory mixing ratio controls the relative strength of the input signals from the audio accessory and the hearing device microphone(s). Johnstone et al (2018) ${ }^{12}$ measured speech recognition in quiet and noise in bilaterally hearingimpaired pediatric $\mathrm{CI}$ recipients (mean age 14 years) using the $\mathrm{T}-\mathrm{Mic}^{\mathrm{TM}}$, the adaptive directional microphone (ADM) Ultrazoom as well as the omnidirectional remote microphone (Pho- nak RemoteMic). Speech recognition significantly improved with the application of both ADM and remote microphone in quiet and noise compared with T-Mic ${ }^{\text {TMT}}$-Mic ${ }^{\mathrm{TM}}$ ?A3B2 ek?> alone. Even though there was a benefit with $\mathrm{ADM}$ and remote microphone, the $\mathrm{CI}$ children performed poorer than the $\mathrm{NH}$ children (Johnstone et al, $2018^{12}$ ). Wolfe and Schafer $(2008)^{31}$ assessed the influence of the mixing ratio on speech recognition in noise in bilaterally hearing-impaired unilateral CI users. In a frontal lecture format, there was no significant difference of objective and self-reported speech performance between the two mixing ratios (50:50 and 30:70, i.e., $50 \%$ or $30 \%$ from CI processor microphone and $50 \%$ or $70 \%$ from coupled audio accessory) applied. In addition, Wolfe and Schafer $(2008)^{31}$ showed that the subjectively judged performance was poorer with the mixing ratio 30:70 when the speech signal was not pointed directly to the recipient's FM transmitter, e.g., in multitalker situations. Hey et al (2009) ${ }^{10}$ compared speech recognition in noise in Cochlear ${ }^{\mathrm{TM}} \mathrm{CI}$ participants using an $\mathrm{FM}$ system with different accessory mixing ratios in two listening situations: a classical lecture format with one frontal speaker and in a listening situation with a lateral speaker. According to Hey et al (2009), ${ }^{10}$ a mixing ratio of $1: 1$ is recommended for listening situations with multiple talkers such as teaching with discussion and a larger mixing ratio for a classical lecture format.

\section{Study Objective}

The aim of the present study is to determine whether SSD CI recipients using a $\mathrm{CI}$ from MED-EL Elektrome- dizinische Gerate GesmbH (Innsbruck, Austria) benefit from different modes of application of Roger ${ }^{\mathrm{TM}}$ in speech recognition for a distant speaker in multisource background noise. Such an improvement is expected, as demonstrated in our study including SSD CI recipients implanted with CI from Cochlear ${ }^{\mathrm{TM}}$ (Wesarg et al, 201927). In addition, the influence of either unilateral (NH ear; $\mathrm{CI}$ ) or bilateral application of Roger ${ }^{\mathrm{TM}}$ should be evaluated in SSD MED-EL CI recipients. Based on the results of Wesarg et al (2019), ${ }^{27}$ our hypothesis is that the use of Roger ${ }^{\mathrm{TM}}$ in SSD CI recipients either on the NH side, the CI side, or bilaterally provides equal benefit. Furthermore, the impact of the type of Roger $^{\mathrm{TM}}$ receiver coupled to the $\mathrm{CI}$ (Roger ${ }^{\mathrm{TM}} \mathrm{X}$ versus Roger ${ }^{\mathrm{TM}}$ MyLink) on speech recognition in noise is investigated. It is expected that the receiver type has an impact on speech recognition because of different signal transmission technologies: digital remote wireless microphone with the Roger ${ }^{\mathrm{TM}} \mathrm{X}$ versus induction hearing loop with Roger $^{\mathrm{TM}}$ MyLink. In addition, different mixing ratios
(MT; T) weighting processor microphone and Roger $^{\mathrm{TM}}$ receiver signals on the $\mathrm{CI}$ side are compared. For a classical lecture format as assessed in our study, we expect the mixing ratio $\mathrm{T}$ to be more beneficial, as the microphone input signal is strongly attenuated with this mixing ratio while the audio accessory input signal is not altered. To complement the objective assessment, we include a questionnaire rating subjective speech perception and identifying device preferences.

\section{Materials and Methods}

\section{Participants}

In this study, included SSD participants were required to use a MED-EL CI and have device experience of $\$ 3$ months, be $\$ 18$ years of age, and speak German as their native language. According to the definition of SSD by Vincent et al (2015), ${ }^{23}$ they had to show (nearly) normal hearing in their betterhearing ear defined as air conduction pure-tone thresholds from $125 \mathrm{~Hz}$ to $4 \mathrm{kHz}$ of equal to or less than $30 \mathrm{~dB} \mathrm{HL}$. In addition, Freiburg monosyllabic word recognition at $65 \mathrm{~dB}$ SPL of $\$ 50 \%$ with the $\mathrm{CI}$ in free field (with the contralateral $\mathrm{NH}$ ear masked) was required.

Eleven adult SSD CI recipients using different implants from MED-EL with the sound processor OPUS 2 were included in this study. - Table 1 displays detailed information on the included $\mathrm{CI}$ recipients.

\section{$\mathrm{Cl}$ and Roger ${ }^{\mathrm{TM}}$ Adjustment}

During testing, the patients used their own sound processor OPUS 2 with their favorite everyday program. - Table 1 shows the coding strategy, volume setting, and microphone sensitivity of the favorite everyday program of the included $\mathrm{CI}$ recipients. Before testing, the processor was technically inspected, including a check of microphone function.

The Roger ${ }^{\mathrm{TM}}$ was used as the remote wireless microphone system. The system's microphone, Roger ${ }^{\mathrm{TM}}$ Pen, was set to handheld mode (lanyard mode) applying an adaptive beamformer yielding a directional microphone characteristic (Bernadette Fulton (Phonak Communications AG), personal communication, 2018).

Three different receivers were applied: $\operatorname{Roger}^{\mathrm{TM}} \mathrm{X}$ and Roger $^{\mathrm{TM}}$ MyLink on the $\mathrm{CI}$ and Roger ${ }^{\mathrm{TM}}$ Focus on the NH ear. For the $\operatorname{Roger}^{\mathrm{TM}} \mathrm{X}$, an accessory mixing ratio of $1: 1$, referred to as MT in the following, was used in which both input signals, from the audio accessory and the hearing device microphone, are added up without attenuation. This ratio is preset and cannot be altered. Before the application of Roger ${ }^{\text {TM }}$ MyLink as the receiver, the telecoil of the OPUS 2 was activated. With Roger ${ }^{\mathrm{TM}}$ MyLink, the mixing ratio was set via the processor's remote control to either MT (1:1, summation of unattenuated microphone and telecoil input) or T (maximum attenuation of microphone input, telecoil input not altered). For application of the Roger ${ }^{\mathrm{TM}}$ MyLink with the mixing ratio MT, the receiver's volume was adjusted individually to match the loudness perceived with the $\operatorname{Roger}^{\mathrm{TM}} \mathrm{X}$. The individual adjustment was required because of the interindividual differences of distance and orientation between the neckloop of Roger ${ }^{\mathrm{TM}}$ MyLink and the OPUS 2 telecoil affecting the loudness with this 


\begin{tabular}{|c|c|c|c|c|c|c|c|c|c|c|c|}
\hline 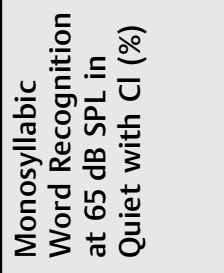 & นn & 8 & $\infty$ & 은 & in & เ̊n & 는 & $\stackrel{\stackrel{n}{r}}{ }$ & in & 음 & | \\
\hline 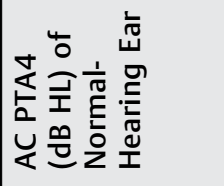 & $\stackrel{\stackrel{L}{\sim}}{\oplus}$ & $\stackrel{n}{r}$ & in & in & \begin{tabular}{|l|}
$\stackrel{n}{N}$ \\
$\infty$ \\
$\infty$
\end{tabular} & $\stackrel{\stackrel{n}{\sim}}{\stackrel{2}{\leftarrow}}$ & \begin{tabular}{|l}
$\stackrel{n}{m}$ \\
$\stackrel{\sim}{n}$
\end{tabular} & $\stackrel{\stackrel{n}{\sim}}{\stackrel{\longrightarrow}{\sim}}$ & $\circ$ & $\stackrel{\sim}{N}$ & 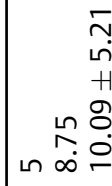 \\
\hline 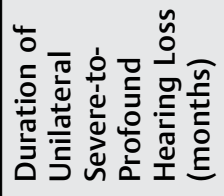 & $\mp$ & $\stackrel{ \pm}{\sim}$ & $\stackrel{\sim}{\simeq}$ & 6 & $\simeq$ & ஜ̆ & : & $\simeq$ & $\frac{\pi}{x}$ & $\stackrel{尺}{\Perp}$ & 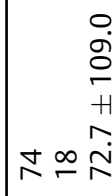 \\
\hline 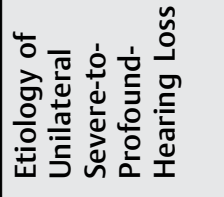 & 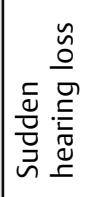 & 竞 & 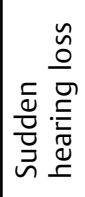 & 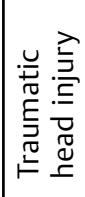 & 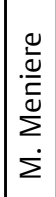 & 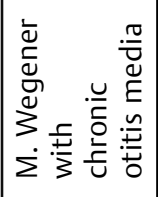 & 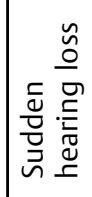 & 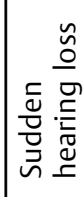 & \begin{tabular}{|l|} 
\\
$\frac{5}{3}$ \\
0 \\
$\frac{5}{5}$ \\
$\frac{5}{5}$ \\
\end{tabular} & 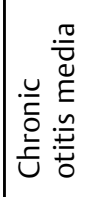 & 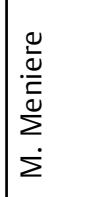 \\
\hline 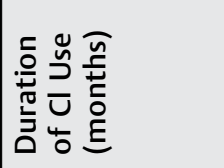 & 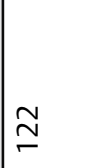 & $\hat{m}$ & $\approx$ & $\approx$ & $\stackrel{\sim}{N}$ & F & 웅 & $\curvearrowright$ & શ & $\ddot{\sim}$ & 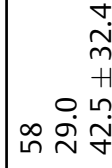 \\
\hline 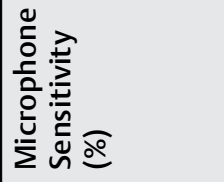 & $\stackrel{\text { Ln }}{N}$ & 朵 & นn & $\stackrel{\text { Ln }}{r}$ & $\stackrel{\text { Ln }}{r}$ & 늣 & 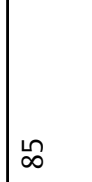 & 迎 & in & $\stackrel{\text { Ln }}{\wedge}$ & $\stackrel{0}{2}$ \\
\hline 蒙 & ○ & $\stackrel{\llcorner}{\wedge}$ & Яా & $\infty$ & $\stackrel{\infty}{\infty}$ & পి & $\infty$ & $\infty$ & $\stackrel{\operatorname{Ln}}{\wedge}$ & $\infty$ & $\stackrel{\infty}{\infty}$ \\
\hline 号 & 芯 & 岕 & 岕 & 厗 & 艺 & $\begin{array}{l}\simeq \\
\frac{n}{4}\end{array}$ & 怠 & 嗠 & 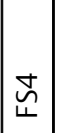 & 鱼 & 壱 \\
\hline \begin{tabular}{|l} 
\\
$\frac{\vec{T}}{\sigma}$ \\
$\frac{\sigma}{\hat{a}}$ \\
$\underline{\underline{E}}$
\end{tabular} & 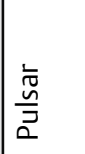 & 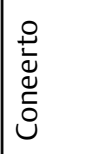 & 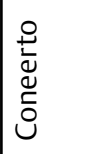 & 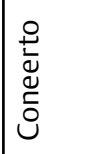 & \begin{tabular}{l}
0 \\
\multirow{2}{*}{} \\
$\stackrel{u}{0}$ \\
0 \\
0
\end{tabular} & 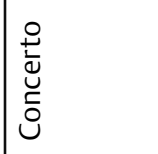 & 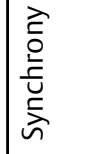 & \begin{tabular}{l}
0 \\
\multirow{2}{u}{} \\
$\stackrel{u}{0}$ \\
0
\end{tabular} & 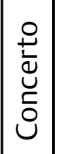 & \begin{tabular}{l}
0 \\
\multirow{2}{*}{} \\
$\stackrel{u}{0}$ \\
0
\end{tabular} & $\mid \begin{array}{l}0 \\
\stackrel{0}{u} \\
\stackrel{u}{0} \\
0 \\
ن\end{array}$ \\
\hline U $\frac{0}{n}$ & $\propto$ & - & - & - & $\propto$ & - & - & $\propto$ & - & - & $\propto$ \\
\hline 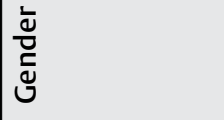 & $\Sigma$ & $\Sigma$ & 3 & $\Sigma$ & 3 & $\Sigma$ & $\Sigma$ & 3 & 3 & 3 & $\Sigma$ \\
\hline 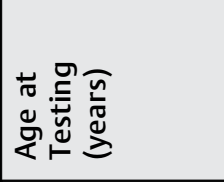 & $\begin{array}{l}0 \\
\text { in } \\
\text { in }\end{array}$ & $\begin{array}{l}0 \\
i \\
m\end{array}$ & $\ddot{\dot{m}}$ & $\stackrel{m}{\stackrel{m}{n}}$ & $\begin{array}{l}\stackrel{n}{1} \\
\stackrel{\infty}{+}\end{array}$ & ஸุ & \begin{tabular}{|l}
$\stackrel{n}{1}$ \\
$\infty$ \\
$\infty$ \\
$n$
\end{tabular} & $\begin{array}{l}\text { G } \\
\text { ผn } \\
\text { กิ }\end{array}$ & $\begin{array}{l}\infty \\
i \\
i n\end{array}$ & $\hat{\mathrm{i}}$ & 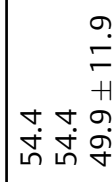 \\
\hline 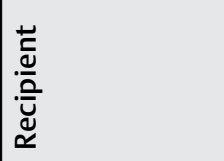 & $\bar{\alpha}$ & $\approx$ & $\stackrel{\tilde{\alpha}}{ }$ & $\underset{\Sigma}{d}$ & $\stackrel{n}{\propto}$ & $\stackrel{\varphi}{\propto}$ & $\not{\alpha}$ & $\stackrel{\infty}{\propto}$ & $\stackrel{2}{\propto}$ & $\frac{0}{\alpha}$ & 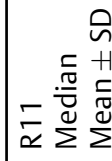 \\
\hline
\end{tabular}


audio induction loop-based signal transmission. This volume adjustment was kept for the application of Roger ${ }^{\mathrm{TM}}$ MyLink with the mixing ratioT. The Roger Focus and the Roger X were applied with a gain of $0 \mathrm{~dB}$.

\section{Stimuli, Equipment, and Test Conditions}

For each test condition, speech recognition in noise was measured in percent correct applying one randomly selected 30-sentence list of the Oldenburg Sentence Test (OLSA) (Wagener et al, 1999a, $\mathrm{b}^{25,26}$ ). As competing noise, a digitally edited first-, second-, third-, and fourth-grade school classroom noise established in the study by Schafer and Thibodeau $(2006)^{19}$ was used. The classroom noise was recorded during students' independent work time and altered so that it matched the long-term average spectrum of the phrases used as speech material in their study (Hearing in Noise Test) (Schafer and Thibodeau, $2006^{19}$ ).

-Figure 1 shows the room dimensions and the experimental setup used in the present study. Speech stimuli and competing noise were presented by a Dell Optiplex 790 PC with a Fireface UC soundcard and five loudspeakers. The recipients were seated $5.5 \mathrm{~m}$ from the speech-presenting single-cone loudspeaker Fostex 6301B (speaker 5). The competing noise was presented in an uncorrelated fashion from four Genelec 8030B loudspeakers (1-4). These speakers were positioned to present the noise toward the middle point of the experimental setup. Sound levels of speech and noise were measured and calibrated as time-averaged sound pressure levels (Leq in $\mathrm{dB}(\mathrm{A})$ ) using an NTi Audio Acousti- lyzer AL1 sound level meter. The speech level was set to $65 \mathrm{~dB}(\mathrm{~A})$ at a distance of $1 \mathrm{~m}$ from the front edge of the loudspeaker 5 , resulting in a speech level of $60.3 \mathrm{~dB}(\mathrm{~A})$ at the recipient's head ( $5.5 \mathrm{~m}$ from speaker 5 ). Noise levels investigated were set to be the same at the location of the recipient's head as well as at the position of the Roger ${ }^{\mathrm{TM}}$ Pen. To assure same noise levels at both positions, calibration was carried out as follows. To begin with, loudspeakers $1-4$ were calibrated at $75 \mathrm{~dB}(\mathrm{~A})$ at a distance of $1 \mathrm{~m}$ in front of each speaker. Following, loudspeakers 1 and 2 were simultaneously calibrated at the position of the Roger ${ }^{\mathrm{TM}}$ Pen, and loudspeakers 3 and 4 were simultaneously calibrated at the recipient's head at $75 \mathrm{~dB}(\mathrm{~A})$ each. Finally, all four noise-presenting loudspeakers were simultaneously calibrated at $75 \mathrm{~dB}(\mathrm{~A})$ at the positions of the Roger ${ }^{\mathrm{TM}}$ Pen as well as the recipient's head. To assure equal noise levels at both positions, adjustments to the simultaneous calibration of loudspeakers 1 and 2, loudspeakers 3 and 4, or all four loudspeakers were made as needed. The Roger ${ }^{\mathrm{TM}}$ Pen was positioned at a distance of $20 \mathrm{~cm}$ in front of loudspeaker 5 at the same height as this speaker, mimicking the vertical position of a Roger ${ }^{\mathrm{TM}}$ Pen worn by a speaker around the neck.

We altered four variables to measure their impact on speech recognition in noise. First, we applied five listening conditions, two no-Roger ${ }^{\mathrm{TM}}$ conditions: $\mathrm{NH}$ ear and $\mathrm{CI}$ turned off ( $\mathrm{NH}$ only) and $\mathrm{NH}$ ear and $\mathrm{CI}$ turned on $(\mathrm{NH}+\mathrm{CI})$ as well as three Roger ${ }^{\mathrm{TM}}$ conditions: $\mathrm{NH}$ ear and $\mathrm{CI}$ with Roger ${ }^{\mathrm{TM}}$ $(\mathrm{NH}+\mathrm{CIRog}), \quad \mathrm{NH}$ ear with Roger ${ }^{\mathrm{TM}}$ Focus and $\mathrm{Cl}$ $(\mathrm{NHRog}+\mathrm{CI})$, and $\mathrm{NH}$ ear with Roger ${ }^{\mathrm{TM}}$ Focus and $\mathrm{CI}$ with Roger $^{\mathrm{TM}}$ (NHRog 1 CIRog) (- Table 2). Second, two different Roger $^{\mathrm{TM}}$ receivers were attached to the CI (Roger ${ }^{\mathrm{TM}} \mathrm{X}$ or Roger $^{\mathrm{TM}}$ MyLink). Furthermore, two accessory mixing ratios (MT; T) were applied during testing. Last, three different noise levels were applied: 55,65 , and $75 \mathrm{~dB}(\mathrm{~A})$.

Speech recognition was tested for all $\operatorname{Roger}^{\mathrm{TM}}$ conditions with the Roger ${ }^{\mathrm{TM}} \mathrm{X}$ attached to the $\mathrm{CI}$ with the mixing ratio MT as well as for both no-Roger ${ }^{\mathrm{TM}}$ conditions at three noise levels, 55, 65, and $75 \mathrm{~dB}(\mathrm{~A})$. With the applied fixed speech level of $65 \mathrm{~dB}(\mathrm{~A})$, this yields signal-to- noise ratios of $5.3,-4.7$, and $-14.7 \mathrm{~dB}$ at the recipient's head, respectively. Speech recognition assessment using fixed levels of speech and noise was chosen according to the Clinical Practice Guidelines Remote Microphone Hearing Assistance Technologies for

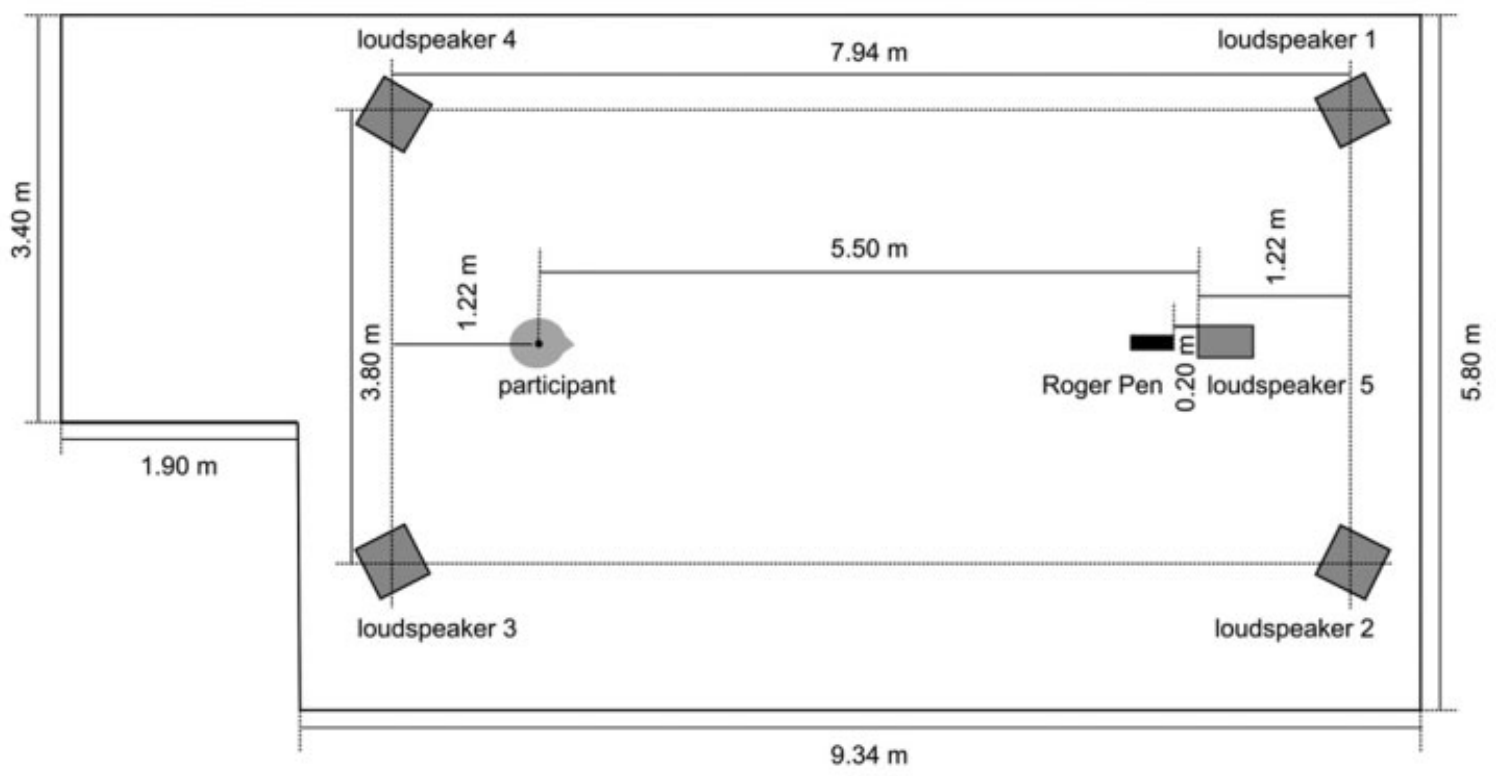

Fig. 1 Room dimensions and experimental setup used for the assessment of speech recognition in competing noise for a distant speaker. 
Table 2 Listening Conditions

\begin{tabular}{|l|l|l|l|}
\hline \multicolumn{2}{|l|}{ No Roger conditions } & NH ear, Cl turned off & No Roger \\
\hline I & NH only & NH ear, Cl (turned on) & Unilateral Roger use on Cl \\
\hline II & NH $1 \mathrm{Cl}$ & NH ear, Cl (turned on) with Roger & Unilateral Roger use on NH ear \\
\hline Roger conditions & NH 1 CIRog & NH ear with Roger Focus, Cl (turned on) & Bilateral Roger use on Cl and NH ear \\
\hline III & NHRog $1 \mathrm{Cl}$ & NH ear with Roger Focus, Cl (turned on) with Roger & \\
\hline IV & NHRog $1 \mathrm{ClRog}$ &
\end{tabular}

Note: $\operatorname{Rog}=$ Roger.

Children and Youth from Birth to 21 Years (American Academy of Audiology, 2011 ${ }^{1}$ ). In addition, for two Roger ${ }^{\mathrm{TM}}$ conditions ( $\mathrm{NH} 1 \mathrm{CIRog}$ and $\mathrm{NHRog}+\mathrm{CIRog}$ ), testing was performed at noise level $75 \mathrm{~dB}(\mathrm{~A})$ with Roger $^{\mathrm{TM}}$ MyLink with either mixing ratio (MT; T).

The sequence of the test conditions was randomized across participants.

For training of speech recognition in classroom noise and accommodation to the procedure of speech recognition assessment administered during testing, two lists of 20 OLSA sentences were presented at $65 \mathrm{~dB}(\mathrm{~A})$, one at a noise level of $55 \mathrm{~dB}(\mathrm{~A})$ and one at $75 \mathrm{~dB}(\mathrm{~A})$ in the no-Roger ${ }^{\mathrm{TM}}$ condition $\mathrm{NH} 1 \mathrm{CI}$ before testing.

\section{Subjective Assessment}

After speech recognition testing, each SSD CI recipient completed a self-reported questionnaire providing information about subjectively perceived speech recognition in the no-Roger ${ }^{\mathrm{TM}} \mathrm{NH}$ only and all Roger ${ }^{\mathrm{TM}}$ listening conditions as well as their preferred listening condition in a work- related environment and in private daily living. The participants were asked to compare the listening conditions presented in the study against the daily listening condition $\mathrm{NH} 1 \mathrm{CI}$. Furthermore, anecdotal information about different listening conditions was gathered. The English translation of the questionnaire is displayed in -Figure $\mathbf{2}$.

\section{Statistical Analysis}

The statistical analysis was carried out in GNU R ( $\mathrm{R}$ Core Team, $2014^{17}$ ). The Shapiro-Wilk test was used to test the data for normal distribution. To analyze the impact of the four within-subject factors (listening condition, receiver type, accessory mixing ratio, and noise level) on speech recognition separate Friedman tests were conducted. Posthoc analyses were administered with pairwise comparison Wilcoxon rank tests using Bonferroni correction to assess the influences of significant main effects. In all analyses, a level of significance of 0.05 was applied.

\section{Results}

\section{Speech Recognition in Noise}

-Figures 3 and $\mathbf{4}$ display the box-and-whisker plots of speech recognition in noise of the 11 SSD CI recipients.

\section{Listening Condition}

To analyze the impact of the listening condition on speech recognition, a separate Friedman test was conducted per noise level. There was a highly significant effect of the listening condition at all three noise levels: $55 \mathrm{~dB}(\mathrm{~A})(p<0.001), 65 \mathrm{~dB}$ (A) $(p<0.001)$, and $75 \mathrm{~dB}(\mathrm{~A})(p<0.001)$. At noise level $55 \mathrm{~dB}$ (A), the Roger ${ }^{\mathrm{TM}}$ conditions NHRog $1 \mathrm{CI}$ and NHRog 1 CIRog yielded significantly better speech recognition than the two no-Roger ${ }^{\mathrm{TM}}$ conditions ( $\mathrm{NH}$ only; $\mathrm{NH} 1 \mathrm{CI}$ ) as well as the Roger $^{\mathrm{TM}}$ condition NH 1 CIRog. At noise level $55 \mathrm{~dB}(\mathrm{~A})$, there was no significant difference between $\mathrm{NH}$ only, $\mathrm{NH} 1 \mathrm{CI}$, and $\mathrm{NH}$ $1 \mathrm{CIRog}$. At noise levels $65 \mathrm{~dB}(\mathrm{~A})$ and $75 \mathrm{~dB}(\mathrm{~A})$, the post hoc analyses revealed that speech recognition in both no-Roger ${ }^{\mathrm{TM}}$ conditions ( $\mathrm{NH}$ only; $\mathrm{NH} 1 \mathrm{CI}$ ) was significantly worse than in the three Roger ${ }^{\mathrm{TM}}$ conditions. Furthermore, at the higher noise levels $65 \mathrm{~dB}(\mathrm{~A})$ and $75 \mathrm{~dB}(\mathrm{~A})$, there was significantly better speech recognition in the listening conditions NHRog $1 \mathrm{CI}$ and NHRog 1 CIRog compared with NH 1 CIRog. At all noise levels, speech recognition did not differ significantly between listening conditions NHRog $1 \mathrm{CI}$ and NHRog 1 CIRog. This means application of Roger ${ }^{\mathrm{TM}}$ on the $\mathrm{NH}$ ear or bilaterally yielded better speech recognition than the unilateral application of Roger $^{\mathrm{TM}}$ on the CI only.

At the lowest noise level ( $55 \mathrm{~dB}(\mathrm{~A}))$, speech recognition in noise showed a ceiling effect in all listening conditions. In addition, a ceiling effect for speech recognition in noise was observed in NHRog $1 \mathrm{CI}$ and NHRog $1 \mathrm{CIRog}$ at $65 \mathrm{~dB}(\mathrm{~A})$. Furthermore, flooring effects were seen in the no-Roger ${ }^{\mathrm{TM}}$ conditions at noise level $75 \mathrm{~dB}(\mathrm{~A})$.

\section{Noise Level}

Separate Friedman tests for each listening condition revealed a highly significant effect of the noise level: $\mathrm{NH}$ only $(p<0.001)$, NH $1 \mathrm{CI}(p<0.001)$, NH 1 CIRog $(p<0.001)$, NHRog $1 \mathrm{CI}(p<0.001)$, and NHRog 1 CIRog $(p<0.001)$. The post-hoc analyses revealed that the SSD CI recipients performed significantly better at the lowest noise level $(55 \mathrm{~dB}(\mathrm{~A}))$ compared with noise levels $65 \mathrm{~dB}(\mathrm{~A})(p<0.001)$ and $75 \mathrm{~dB}(\mathrm{~A})(p<0.001)$. Speech recognition at $65 \mathrm{~dB}(\mathrm{~A})$ was significantly better than at $75 \mathrm{~dB}(\mathrm{~A})(p<0.001)$.

\section{Receiver Type and Accessory Mixing Ratio}

There was no significant difference in effect of receiver type in the listening conditions NH 1 CIRog $(p>0.05)$ and NHRog 1 


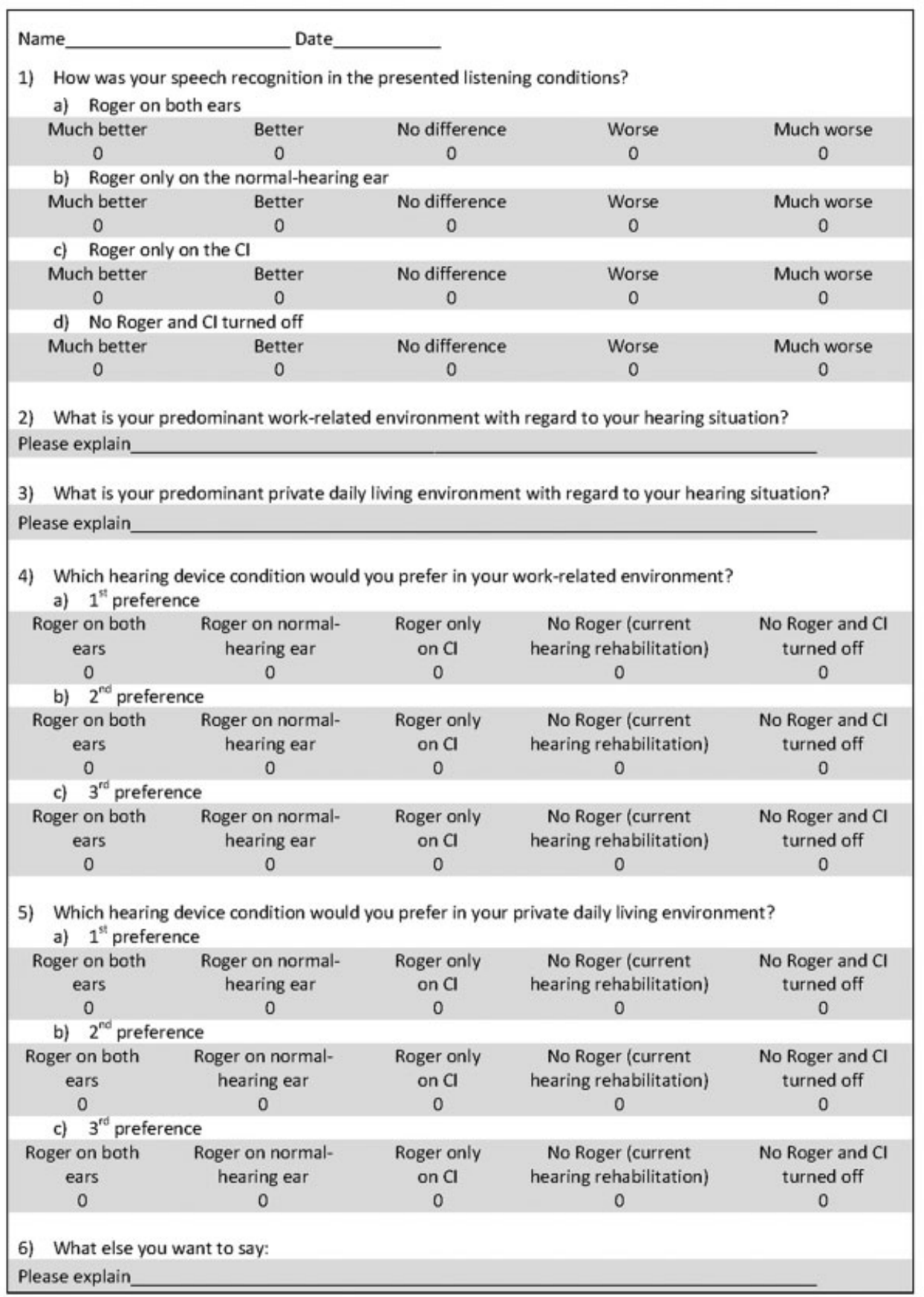

Fig. 2 Self-report questionnaire used in the present study, translated from German into English.

CIRog $(p>0.05)$ at noise level $75 \mathrm{~dB}(\mathrm{~A})$. Furthermore, there was no significant impact of the accessory mixing ratio on speech recognition in the listening conditions $\mathrm{NH} 1 \mathrm{CIRog}$ $(p>0.05)$ and NHRog 1 CIRog $(p>0.05)$ at noise level $75 \mathrm{~dB}$ (A).

\section{Questionnaire}

All SSD CI recipients rated their speech recognition with Roger ${ }^{\mathrm{TM}}$, attached unilaterally on either ear or bilaterally, as "much better" or "better" than without Roger ${ }^{\mathrm{TM}}$. Except one recipient reporting "no difference," all recipients evaluated speech recognition without $\mathrm{CI}$ (only with the $\mathrm{NH}$ ear) as "worse" or "much worse" than with the $\mathrm{CI}$ or with each of the three Roger ${ }^{\mathrm{TM}}$ applications. For their work-related environment, five of the eleven recipients preferred the bilateral application of $\operatorname{Roger}^{\mathrm{TM}}$ and three of them the unilateral application on the $\mathrm{NH}$ ear. As two recipients had already retired, they did not specify their predominant work-related listening condition. One recipient did not complete the questionnaire. For their private daily living, six recipients preferred the bilateral Roger ${ }^{\mathrm{TM}}$ application, three recipients the application of Roger ${ }^{\mathrm{TM}}$ only on the $\mathrm{CI}$, and one recipient the everyday no-Roger ${ }^{\mathrm{TM}}$ listening condition $\mathrm{NH} 1 \mathrm{CI}$. Anecdotally, one recipient described the application of Roger ${ }^{\mathrm{TM}}$ as follows: "With Roger you have the feeling of being able to participate in society without restrictions again." 


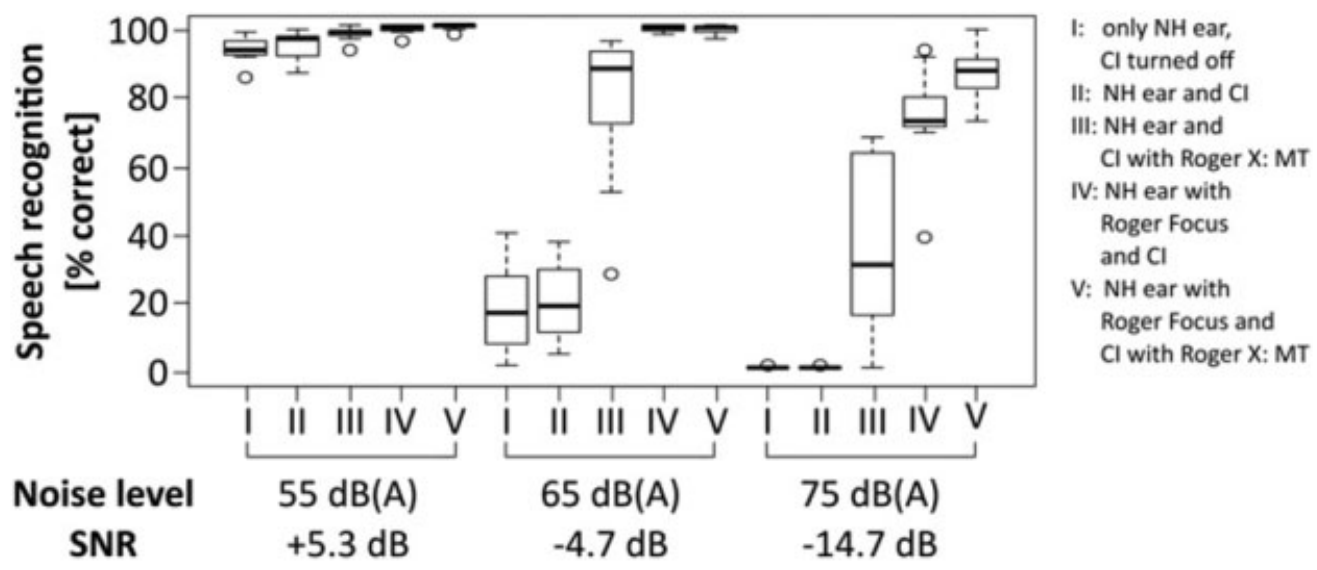

Fig. 3 Box-and-whisker plots of speech recognition of 11 SSD Cl recipients obtained for OLSA sentences presented at $65 \mathrm{~dB}(\mathrm{~A})$ at 3 noise levels of competing classroom noise for each of five listening conditions. For two Roger ${ }^{\mathrm{TM}}$ conditions (III and V) tested at $75 \mathrm{~dB}(\mathrm{~A})$, the data displayed includes both receiver types (Roger ${ }^{\mathrm{TM}} \mathrm{X}$; Roger ${ }^{\mathrm{TM}}$ MyLink) as well as both accessory mixing ratios (both receivers: T; Roger ${ }^{\mathrm{TM}}$ MyLink: MT). Speech was presented at $65 \mathrm{~dB}(\mathrm{~A})$ as measured at $1 \mathrm{~m}$ from the speaker, whereas the listener sat $5.5 \mathrm{~m}$ away from the speaker.

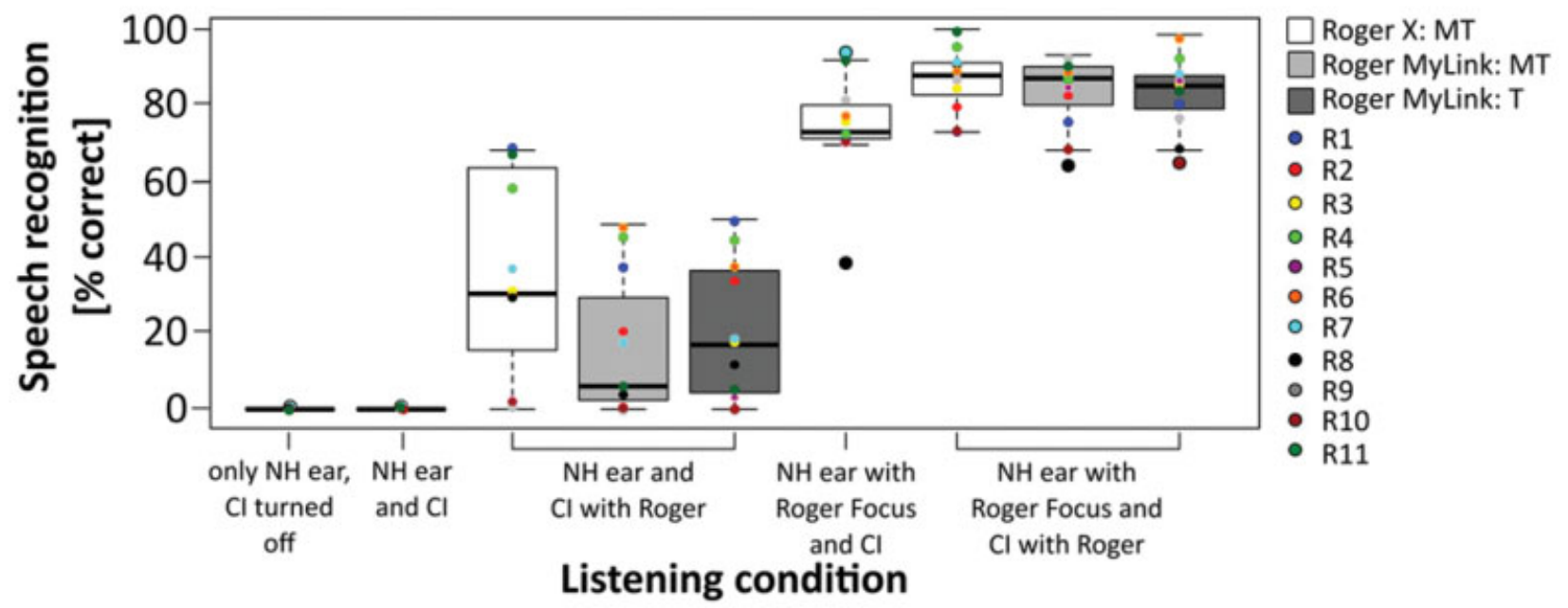

Fig. 4 Box-and-whisker plots of speech recognition of 11 SSD Cl recipients obtained for OLSA sentences presented at $65 \mathrm{~dB}(\mathrm{~A})$ at a noise level of $75 \mathrm{~dB}(\mathrm{~A})$ for two different receivers (Roger ${ }^{\mathrm{TM}} \mathrm{X}$; Roger ${ }^{\mathrm{TM}}$ MyLink) on the $\mathrm{Cl}$ and two different accessory mixing ratios (both receivers: $\mathrm{MT}$; Roger ${ }^{\mathrm{TM}}$ MyLink: T). Speech was presented at $65 \mathrm{~dB}(\mathrm{~A})$ as measured at $1 \mathrm{~m}$ from the speaker, whereas the listener sat $5.5 \mathrm{~m}$ away from the speaker. R1-R11, SSD CI recipients 1-11. (This figure appears in color in the online version of this article.)

\section{Discussion}

Various studies have shown that speech recognition in noise and localization of sound sources in SSD participants significantly improve after cochlear implantation (Lieu, 2004; ${ }^{13}$ Vermeire and Van de Heyning, 2009; ${ }^{22}$ Buechner et al, 2010; ${ }^{4}$ Arndt et al, 2011; Jacob et al, 2011; ${ }^{11}$ Firszt et al, $2012 ;{ }^{7}$ Tavora-Vieira et al, 2015; ${ }^{20}$ Friedmann et al, 2016; ${ }^{8}$ Arndt et al, $2017^{3}$ ). Nevertheless, SSD CI recipients are still exposed to challenging listening conditions with distant speakers or multisource competing background noise, and hearing rehabilitation with the $\mathrm{CI}$ has shown to provide limited benefit (Wolfe et al, 2013; ${ }^{30}$ Thibodeau, 2014; ${ }^{21}$ Wolfe et al, $2015 ;{ }^{29}$ De Ceulaer et al, 2016; ${ }^{5}$ Wesarg et al, 2019 ${ }^{27}$ ). In these conditions, the successful application of the remote wireless technology, Roger $^{\mathrm{TM}}$, has already been demonstrated in bilaterally moderate-to-severe hearing-impaired participants provided with HA (s), Cl(s), or bimodal devices (Wolfe et al, 2013;30 Thibodeau, 2014; ${ }^{21}$ De Ceulaer et al, $2017^{6}$ ) as well as in SSD CI recipients (with CI from Cochlear ${ }^{\mathrm{TM}}$ ) and $\mathrm{NH}$ participants (Wesarg et al, $\left.2019^{27}\right)$. The aim of the present study is to measure the benefit of the remote wireless technology, Roger ${ }^{\mathrm{TM}}$, in SSD CI recipients using a CI from MED-EL and to compare the unilateral application of Roger ${ }^{\mathrm{TM}}$ on the $\mathrm{NH}$ ear or on the $\mathrm{CI}$ and the bilateral Roger $^{\mathrm{TM}}$ use on both ears. In addition, we assessed the effects of the type of Roger ${ }^{\mathrm{TM}}$ receiver (Roger ${ }^{\mathrm{TM}} \mathrm{X}$; Roger ${ }^{\mathrm{TM}}$ MyLink) and accessory mixing ratio (MT; T).

The present study demonstrates a significant benefit of the application of Roger $^{\mathrm{TM}}$ in SSD CI recipients in a frontal lecture like school classroom situation. As we applied a classroom noise, our results are primarily applicable to this specific listening situation. This is one wide-spread everyday-life situation that we were able to reproduce in an experimental setting and thus, Roger ${ }^{\mathrm{TM}}$ should be considered 
for recommendation by ENT physicians and audiologists as an effective technology to improve communication in these recipients, particularly in this situation. Based on our setup presuming the benefit of Roger in other everyday-life situations such as lecture halls or restaurant settings is difficult. This is due to a potential large impact of noise and room characteristics on the benefit with remote microphone technology. Therefore, future research may explore the effect ofnoise or room characteristics on this benefit for a variety of real-life listening environments using setups appropriately mimicking these environments.

Including SSD CI recipients provided with a CI from MED-EL, the present study expands previous findings from a recent study in SSD CI recipients with a CI from Cochlear ${ }^{\mathrm{TM}}$ (Wesarg et al, $2019^{27}$ ). Therefore, it seems that with the application of Roger $^{\mathrm{TM}}$ technology, a benefit in speech recognition in noise is evident in SSD CI recipients independently of CI sound processor technology. Multiple studies, including the present study, have shown that the Roger ${ }^{\mathrm{TM}}$ system has a robust physical effect on speech recognition in noise for distant speakers independent of the type of HA or CI (Wolfe et al, 2013; 30 Thibodeau, 2014; ${ }^{21}$ Wolfe et al, 2015; ${ }^{29}$ De Ceulaer et al, $2016 ;^{5}$ Wesarg et al, $2019^{27}$ ).

In both studies, Wesarg et al (2019) ${ }^{27}$ and the present study, no significant difference was detected between the unilateral application on the $\mathrm{NH}$ ear and bilateral application. One novel finding of the present study concerns the effect of Roger ${ }^{\mathrm{TM}}$ application on speech recognition in noise. While the present study revealed better speech recognition with the application of Roger ${ }^{\mathrm{TM}}$ on the $\mathrm{NH}$ ear or bilaterally than on the $\mathrm{CI}$ alone, there was no significant difference between unilateral ( $\mathrm{NH}$ or CI) and bilateral application as obtained by Wesarg et al (2019). ${ }^{27}$ For unilateral application of Roger $^{\mathrm{TM}}$ on the $\mathrm{CI}(\mathrm{NH}$ $1 \mathrm{CIRog}$ ), speech recognition in noise is potentially influenced by the speech performance obtained with the $\mathrm{CI}$ alone, and a poorer performance may yield less speech recognition with a remote wireless system on the $\mathrm{Cl}$. Therefore, the poorer speech recognition with the unilateral application of Roger $^{\mathrm{TM}}$ on the $\mathrm{CI}$ might be due to the poorer $\mathrm{CI}$ speech performance of the SSD $\mathrm{CI}$ recipients in the present study compared with the SSD CI recipients included in Wesarg et al (2019). ${ }^{27}$ Summarizing the outcomes of the present study, the unilateral application ofRoger $^{\mathrm{TM}}$ on the $\mathrm{NH}$ ear or the $\mathrm{CI}$ as well as the bilateral Roger $^{\mathrm{TM}}$ application can be recommended to SSD CI recipients. Even though, unilateral Roger ${ }^{\mathrm{TM}}$ application on the $\mathrm{CI}$ should be mainly recommended to SSD CI recipients with good speech recognition with the $\mathrm{CI}$. A unilateral application might be preferable, as it is more cost-effective. However, subjective preferences should be taken into consideration as the subjective assessment showed that most of the included recipients preferred the bilateral application of Roger ${ }^{\mathrm{TM}}$ for their work-related environment and their private daily living.

Furthermore, speech recognition in noise with two different Roger ${ }^{\mathrm{TM}}$ receivers (Roger ${ }^{\mathrm{TM}} \mathrm{X}$, Roger ${ }^{\mathrm{TM}}$ MyLink) coupled with the $\mathrm{CI}$ were assessed in the present study revealing no significant difference at the only common noise level $(75 \mathrm{~dB}$ (A)). Based on this result, both Roger $^{\mathrm{TM}}$ receivers can be recommended to SSD CI recipients using MED-EL processors to improve speech recognition in noise. Whereas there are no significant differences in effects of Roger ${ }^{\mathrm{TM}} \mathrm{X}$ and MyLink, there is a trend toward better performance with $\operatorname{Roger}^{\mathrm{TM}} \mathrm{X}$ for several participants. Clinical implication may be to evaluate outcomes with both options for SSD CI recipients on an individual basis, when possible in addition to considering subjective preference. Roger ${ }^{\mathrm{TM}}$ MyLink enables the application of the Roger ${ }^{\mathrm{TM}}$ transmitters in hearing- impaired participants using $\mathrm{HAs}$ or $\mathrm{Cl}$ sound processors with an integrated telecoil even without an audio input socket in the hearing device.

In contrast to Roger ${ }^{\mathrm{TM}} \mathrm{X}$, the Roger ${ }^{\mathrm{TM}}$ MyLink offers the additional option to apply different accessory mixing ratios. In the present study, speech recognition in noise was measured for the Roger ${ }^{\mathrm{TM}}$ conditions $\mathrm{NH}+\mathrm{CIRog}$ and NHRog + CIRog with two different accessory mixing ratios (MT; T) and two different receivers (Roger ${ }^{\mathrm{TM}} \mathrm{X}$ with mixing ratio MT; Roger $^{\mathrm{TM}}$ MyLink with mixing ratios MT or T) attached to the $\mathrm{CI}$. For the mixing ratio MT, input signals from both the microphone and the telecoil are added up without attenuation. By contrast, for the mixing ratio $\mathrm{T}$, the microphone input signal is strongly attenuated, whereas the telecoil input signal is not altered. No significant effect of the mixing ratio was found. This contradicts our assumption that SSD CI recipients should have obtained better speech recognition in noise with T than MT. This assumption is based on a better SNR of the pure telecoil input signal with $\mathrm{T}$ compared with the SNR of the summed microphone and telecoil input with MT. The SNR of the microphone input signal roughly corresponds to the SNR at the recipient's head, i.e., amounts to $5.3,-4.7$, or $-14.7 \mathrm{~dB}$ for the assessed noise levels, 55, 65, and $75 \mathrm{~dB}(\mathrm{~A})$. Compared with these SNRs, the SNRs of the signals at the telecoil input are higher because of two reasons. The radio-transmitted signals reaching the receiver were recorded near the speech-presenting speaker with a speech sound level $4.7 \mathrm{~dB}$ larger than at the recipient's head. In addition to this robust physical effect of compensating for the distance-dependent reduction in speech level by radio transmission, Roger ${ }^{\mathrm{TM}}$ applies an adaptive-gain adjustment and noise cancellation (Phonak AG, 2013 ${ }^{14}$ ) further improving the SNR of the telecoil input signal. However, there was no effect of accessory mixing ratio on speech recognition in noise in the conditions $\mathrm{NH} 1 \mathrm{CIRog}$ and NHRog + CIRog. On the one hand, this might be attributable to a ceiling effect for the NHRog + CIRog condition. This ceiling effect could be due to the dominating effect of Roger application on the NH ear. As shown in our results, at the background noise levels $65 \mathrm{~dB}(\mathrm{~A})$ and $75 \mathrm{~dB}(\mathrm{~A})$, SSD CI recipients benefited significantly more from Roger application in the $\mathrm{NH}$ ear or bilaterally than from unilateral application on the $\mathrm{CI}$, $\mathrm{NH}+\mathrm{CIRog}$. Therefore, different mixing ratios for the bilateral Roger application might have no significant effect on speech recognition because of the dominance of the $\mathrm{NH}$ performance. On the other hand, mixing ratios MT and T had no significant impact on speech recognition in the $\mathrm{NH} 1 \mathrm{CIRog}$ condition. This might be attributed to an only small difference in SNR between pure telecoil input signal with $\mathrm{T}$ and the summed microphone and telecoil input signal with MT.

The lacking difference in speech recognition between mixing ratios is in line with Wolfe and Schafer $(2008)^{31}$ 
who investigated the two different mixing ratios 50:50 and 30:70 between the input of an FM receiver attached to a CI processor and the $\mathrm{CI}$ processor micro- phone(s) in bilaterally hearing-impaired $\mathrm{CI}$ recipients. They found no difference between the two different mixing ratios in either objectively or subjectively assessed speech recognition in noise. Potentially, the difference between both mixing ratios is too small to allow for a significant impact on speech recognition. By contrast, Hey et al (2009) $)^{10}$ revealed an improvement of speech performance in noise with increasing mixing ratio, corresponding to decreasing microphone input and constant FM receiver input, assessing speech reception thresholds in a classical lecture format for unilateral application of an FM system in postlingually deafened uni- or bilateral CI recipients. However, the discussed studies significantly differed in methodology which might explain the different findings. In the present study as well as in the study of Wolfe and Schafer $(2008),{ }^{31}$ speech recognition was assessed in multitalker speech babble (classroom noise or four-talker babble) at fixed levels of speech $(60.3 \mathrm{~dB}(\mathrm{~A})$ or $65 \mathrm{~dB}(\mathrm{~A})$, respectively) and noise $(75 \mathrm{~dB}(\mathrm{~A})$ or $60 \mathrm{~dB}(\mathrm{~A})$, respectively), whereas Hey et al $(2009)^{10}$ measured speech reception thresholds in unmodulated speech-simulating noise (OLnoise) varying the speech level at a fixed noise level ( $65 \mathrm{~dB} \mathrm{SPL})$.

However, the mixing ratio $\mathrm{T}$ might not be appropriate for multiple-talker situations occurring e.g., during conferences. This claim is supported by the study by Wolfe and Schafer $(2008)^{31}$ who revealed a poorer speech performance in noise with a mixing ratio of 30:70 compared with 50:50 when the speech signal was not pointed directly to the FM transmitter. Hey et al (2009) ${ }^{10}$ suggested the application of different mixing ratios in different listening situations, a mixing ratio of 3:1 or higher for the classical lecture format and a mixing ratio of 1:1 in multitalker settings, like a conference or group work. Furthermore, in the bilateral Roger ${ }^{\mathrm{TM}}$ condition, speech recognition approached ceiling level in the present study; thus, a possible effect ofmixing ratio applied with $\operatorname{Roger}^{\mathrm{TM}}$ on the $\mathrm{Cl}$ might be obscured by the $\mathrm{NH}$ ear performance.

According to the Clinical Practice Guidelines (American Academy of Audiology, 2011 ${ }^{1}$ ), fixed levels of speech and noise, i. e., a fixed SNR, were used in the present study instead of adaptive speech-in-noise testing. In addition, the application of fixed levels of speech and noise was chosen to allow for comparison of the present study with many previous studies (Wolfe et al, 2013; ${ }^{30}$ Thibodeau, 2014 ${ }^{21}$ ), including our study published in Wesarg et al (2019). ${ }^{27}$ However, fixed SNR have resulted in floor as well as ceiling effects in speech recognition in both the present study and the study by Wesarg et al (2019). ${ }^{27}$ To avoid floor and ceiling effects, in future studies investigating benefits of remote wireless microphone technology, speech reception thresholds using adaptive procedures might be measured. However, these assessment procedures should have been standardized before their application.

Further research investigating various mixing ratios in different listening situations in SSD CI recipients would be interesting, and clinical recommendations based on the results could help these recipients to select mixing ratios with their remote wireless technology to be most beneficial for communication in their work- related environment and private daily living. In addition, the comparison of different remote wireless microphone technologies in adult SSD CI recipients, similar to the study conducted by Razza et al (2017), ${ }^{18}$ would help to improve clinical recommendations.

\section{Conclusions}

The digital remote microphone system, Roger ${ }^{\mathrm{TM}}$, significantly improves speech recognition for distant speakers $(5.5 \mathrm{~m})$ in multitalker competing noise at higher noise levels $(65 \mathrm{~dB}(\mathrm{~A})$ and $75 \mathrm{~dB}(\mathrm{~A})$ ) in SSD MED-EL CI recipients. Speech recognition in noise is significantly better with the application of Roger $^{\mathrm{TM}}$ on the NH ear or bilaterally than with Roger $^{\mathrm{TM}}$ on the $\mathrm{Cl}$ alone.

The type of Roger ${ }^{\mathrm{TM}}$ receiver attached to the $\mathrm{CI}$ processor (Roger ${ }^{\mathrm{TM}} \mathrm{X}$; Roger ${ }^{\mathrm{TM}}$ MyLink) did not affect speech recognition in noise. In the investigated listening situation with one frontal speaker, both assessed mixing ratios (MT; T) yielded comparable speech recognition. The self-assessments of the recipients revealed a preference for Roger $^{\mathrm{TM}}$ application and especially bilateral Roger ${ }^{\mathrm{TM}}$ application in their work-related environment. To sum up, for SSD CI recipients, the unilateral application of Roger ${ }^{\mathrm{TM}}$ on the $\mathrm{NH}$ ear or on the $\mathrm{CI}$ as well as the bilateral application can be recommended. Furthermore, both receivers (Roger ${ }^{\mathrm{TM}} \mathrm{X}$ and Roger ${ }^{\mathrm{TM}}$ MyLink) as well as either mixing ratio (MT with both receivers; $\mathrm{T}$ with Roger $^{\mathrm{TM}}$ MyLink) can be endorsed.

\section{Abbreviations}

ADM adaptive directional microphone

CI cochlear implant

FM frequency modulation

HA hearing aid

$\mathrm{NH}$ normal hearing

OLSA Oldenburg Sentence Test

SSD singlesided deafness

Funding

The authors of this manuscript did not receive any monetary compensation for this study. Phonak GmbH (Fellbach-Oeffingen, Germany) provided a Roger ${ }^{\mathrm{TM}}$ system loaner to CI-Centrum Rhein-Mosel-Lahn for this study. This study was conducted in accordance with the guidelines of the Declaration of Helsinki (Washington, World Medical Association, 2013) and was approved by the ethics committee of the Landesarztekammer RheinlandPfalz.

\section{Acknowledgments}

The authors thank the association "Taube Kinder lernen Horen e.V." for its considerable support of the cochlear implant rehabilitation center in Freiburg. In addition, we thank Slawa Gorelik for his assistance in data collection as 
well as Roland Laszig for his assistance in the conception and design of the project.

\section{References}

1 American Academy of Audiology. Clinical Practice Guidelines Remote Microphone Hearing Assistance Technologies for Children and Youth from Birth to 21 Years (Includes Supplement A). 2011https://audiology-web.s3.amazonaws.com/migrated/HAT_Guidelines_Supplement_A.pdf_53996ef7758497.54419000.pdf. Accessed April 6, 2019

2 Arndt S, Aschendorff A, Laszig R, Beck R, Schild C, Kroeger S, Ihorst G, Wesarg T. Comparison of pseudobinaural hearing to real binaural hearing rehabilitation after cochlear implantation in patients with unilateral deafness and tinnitus. Otol Neurotol 2011;32(01):39-47

3 Arndt S, Laszig R, Aschendorff A, Hassepaß F, Wesarg T. Cochlear implant treatment of patients with single-sided deafness or asymmetric hearing loss. HNO 2017;65(07):586-598

4 Buechner A, Brendel M, Lesinski-Schiedat A, Wenzel G, FrohneBuechner C, Jaeger B, Lenarz T. Cochlear implantation in unilateral deaf subjects associated with ipsilateral tinnitus. Otol Neurotol 2010;31(09):1381-1385

5 De Ceulaer G, Bestel J, Mulder HE, Goldbeck F, de Varebeke SP, Govaerts PJ. Speech understanding in noise with the Roger Pen, Naida CI Q70 processor, and integrated Roger 17 receiver in a multi-talker network. Eur Arch Otorhinolaryngol 2016;273(05): 1107-1114

6 De Ceulaer G, Pascoal D, Vanpoucke F, Govaerts P. The use of cochlear's SCAN and wireless microphones to improve speech understanding in noise with the Nucleus $6 \circledast$ CP900 processor. Int JAudiol 2017;56(11):837-843

7 Firszt JB, Holden LK, Reeder RM, Waltzman SB, Arndt S. Auditory abilities after cochlear implantation in adults with unilateral deafness: a pilot study. Otol Neurotol 2012;33(08):1339-1346

8 Friedmann DR, Ahmed OH, McMenomey SO, Shapiro WH, Waltzman SB, Roland JT Jr. Single-sided deafness cochlear implantation: candidacy, evaluation, and outcomes in children and adults. Otol Neurotol 2016;37(02):e154-e160

9 Giolas TG, Wark DJ. Communication problems associated with unilateral hearing loss. J Speech Hear Disord 1967;32(04): 336-343

10 Hey M, Anft D, Hocke T, Scholz G, Hessel H, Begall K. [Influence of mixing ratios of a FM-system on speech understanding of CIusers]. Laryngorhinootologie 2009;88(05):315-321 (in German)

11 Jacob R, Stelzig Y, Nopp P, Schleich P. [Audiological results with cochlear implants for single-sided deafness]. HNO 2011;59(05): 453-460 (in German)

12 Johnstone PM, Mills KE, Humphrey EL, Yeager KR, Jones EE, McElligott KJ, Pierce A, Agrawal S, Froeling C, Little J. Using microphone technology to improve speech perception in noise in children with cochlear implants. J Am Acad Audiol 2018;29(09):814-825

13 Lieu JE. Speech-language and educational consequences of unilateral hearing loss in children. Arch Otolaryngol Head Neck Surg 2004;130(05):524-530

14 Phonak AG. Phonak InsightVRoger Pen-Bridging the Understanding Gap. 028-0933-02/V1.00/2013-09/8G/. 2013https://www.phonakpro.com/content/dam/phonakpro/gc_hq/en/resources/evidence/ white_paper/documents/technical_paper/Insight_Roger_Pen_0280933.pdf. Accessed June 20, 2017

15 Phonak AG. Roger ${ }^{\mathrm{TM}}$ Table Mic-User Guide. 2016https://www. phonak.com/content/dam/phonak/HQ/en/solution/accessories/ roger_table_mic/documents/user_guide_roger_table_mic_0294004.pdf. Accessed June 5, 2018

16 Phonak AG. Roger ${ }^{\mathrm{TM}}$ Touchscreen Mic-UserGuide. 2017https:// www.phonak.com/content/dam/phonak/gc_se/en/solution/accessories/roger_technology/documents/User_Guide_Roger_Touchscreen_Mic_GB_V1\%2000_029-3222-02.pdf. Accessed June 5, 2018

17 R Core Team. R: A Language and Environment for Statistical Computing. Vienna, Austria: R Foundation for Statistical Computing. (Online) 2014https://www.R-project.org/. Accessed June 20, 2018

18 Razza S, Zaccone M, Meli A, Cristofari E. Evaluation of speech reception threshold in noise in young Cochlear ${ }^{\mathrm{TM}}$ Nucleus ${ }^{\circledR}$ system 6 implant recipients using two different digital remote microphone technologies and a speech enhancement sound processing algorithm. Int J Pediatr Otorhinolaryngol 2017;103:71-75

19 Schafer EC, Thibodeau LM. Speech recognition in noise in children with cochlear implants while listening in bilateral, bimodal, and FM system arrangements. Am J Audiol 2006;15(02):114-126

20 Tavora-Vieira D, De Ceulaer G, Govaerts PJ, Rajan GP. Cochlear implantation improves localization ability in patients with unilateral deafness. Ear Hear 2015;36(03):e93-e98

21 Thibodeau L. Comparison of speech recognition with adaptive digital and FM remote microphone hearing assistance technology by listeners who use hearing aids. Am J Audiol 2014;23(02): 201-210

22 Vermeire K, Van de Heyning P. Binaural hearing after cochlear implantation in subjects with unilateral sensorineural deafness and tinnitus. Audiol Neurootol 2009;14(03):163-171

23 Vincent C, Arndt S, Firszt JB, Fraysse B, Kitterick PT, Papsin BC, Snik A, Van de Heyning P, Deguine O, Marx M. Identification and evaluation of cochlear implant candidates with asymmetrical hearing loss. Audiol Neurootol 2015;20(1 Suppl):87-89

24 Vroegop JL, Dingemanse JG, Homans NC, Goedegebure A. Evaluation of a wireless remote microphone in bimodal cochlear implant recipients. Int J Audiol 2017;56(09):643-649

25 Wagener K, Brand T, Kollmeier B. Entwicklung und Evaluation eines Satztests in deutscher Sprache III: Evaluation des Oldenburger Satztests. Z Audiol 1999a;38(03):86-95

26 Wagener K, Kuhnel V, Kollmeier B. Entwicklung und Evaluation eines Satztests in deutscher Sprache I: Design des Oldenburger Satztests. Z Audiol 1999b;38(01):4-15

27 Wesarg T, Arndt S, Wiebe K, Schmid F, Huber A, Mulder HE, Laszig $\mathrm{R}$, Aschendorff A, Speck I. Speech recognition in noise in singlesided deaf cochlear implant recipients using digital wireless adaptive microphone technology. J Am Acad Audiol 2019;30 (07):607-618

28 Wie OB, Pripp AH, Tvete O. Unilateral deafness in adults: effects on communication and social interaction. Ann Otol Rhinol Laryngol 2010;119(11):772-781

29 Wolfe J, Morais M, Schafer E, Agrawal S, Koch D. Evaluation of speech recognition of cochlear implant recipients using adaptive, digital remote microphone technology and a speech enhancement sound processing algorithm. J Am Acad Audiol 2015;26(05): 502-508

30 Wolfe J, Morais M, Schafer E, Mills E, Mulder HE, Goldbeck F, Marquis F, John A, Hudson M, Peters BR, Lianos L. Evaluation of speech recognition of cochlear implant recipients using a personal digital adaptive radio frequency system. J Am Acad Audiol 2013;24(08): 714-724

31 Wolfe J, Schafer EC. Optimizing the benefit of sound processors coupled to personal FM systems. J Am Acad Audiol 2008;19(08): 585-594 